\title{
Pharmacogenetic information for patients on drug labels
}

This article was published in the following Dove Press journal:

Pharmacogenomics and Personalized Medicine

3 October 2014

Number of times this article has been viewed

\section{Susanne B Haga \\ Rachel Mills \\ Jivan Moaddeb}

Center for Applied Genomics and Precision Medicine, Department of Medicine, Duke University, Durham, NC, USA
Correspondence: Susanne B Haga Center for Applied Genomics and Precision Medicine, Department of Medicine, Duke University, 304 Research Drive, Box 9014I, Durham, NC 27708, USA

Tel +19196840325

Fax + I 9196136448

Email susanne.haga@duke.edu
Abstract : Advances in pharmacogenetic research have improved our understanding of adverse drug responses and have led to the development of pharmacogenetic tests and targeted drugs. However, the extent of the communication process and provision of information to patients about pharmacogenetics is unclear. Pharmacogenetic information may be included in sections of a drug's package insert intended for patients, which is provided directly to patients or communicated via the health provider. To determine what pharmacogenetic information, if any, is included in patient-targeted sections of the drug label, we reviewed the labels listed in the US Food and Drug Administration's Table of Pharmacogenomic Biomarkers in Drug Labels. To date, 140 drugs include pharmacogenetic-related information in the approved label. Our analysis revealed that pharmacogenetic information is included in patient-targeted sections for a minority $(n=29$; $21 \%$ ) of drug labels, with no obvious pattern associated with the inclusion of pharmacogenetic information. Therefore, patients are unlikely to learn about pharmacogenetics through written materials dispensed with the drug. Given that there are also inconsistencies with regard to inclusion of pharmacogenetic information in the patient counseling information section, it is also unlikely that patients are receiving adequate pharmacogenetic information from their provider. The inconsistent presence of pharmacogenetic information in patient-targeted sections of drug labels suggests a need to review the criteria for inclusion of information in patient-targeted sections in order to increase consistency and patient knowledge of pharmacogenetic information. Keywords: pharmacogenomics, pharmacogenetics, US Food and Drug Administration, drug safety, patient education

\section{Introduction}

Pharmacogenetic testing involves the analysis of genetic variants associated with risk of an adverse drug response or likelihood of response. Pharmacogenetic testing is a de facto requirement for drugs indicated for patients with specific genetic changes (otherwise known as a companion diagnostic), but testing is considered optional to assess a patient's rate of drug metabolism, prodrug conversion, or variation in a drug target. ${ }^{1}$ To date, 140 drugs approved by the United States Food and Drug Administration (FDA) include pharmacogenetic-related information in their labels. ${ }^{2}$ Based on drug utilization data from a single large pharmacy benefits manager, Frueh et al estimated that almost a quarter of patients in 2006 (approximately 8.8 million) were prescribed drugs for which pharmacogenetic information was included in the drug labels. ${ }^{1}$ Almost a decade later, we would anticipate this number to have increased substantially. With the increasing number of drugs prescribed with pharmacogenetic information and movement toward more patient-centered care, providing patients with information about 
their current treatment(s) may promote greater engagement, comprehension, and satisfaction, potentially improving medication adherence. ${ }^{3}$

Drug labels primarily serve to inform providers and other users about the use of a drug. Guidance is available regarding the specific content and format for each section of the drug label. ${ }^{4,5}$ The FDA amended the labeling rules in 2006 to include a patient counseling information section (section 17) for the provider to discuss with the patient regarding the safe and appropriate use of the prescribed drug. ${ }^{6}$ Prior to 2006 , the drug label contained a section entitled "Information for patients" in the precautions section of the drug label. In addition, a few sections of the FDA-approved drug label are intended to be provided directly to patients upon dispensation for some drugs, namely patient package inserts and medication guides. Patient package inserts are required to provide information for the safe use of oral contraceptives ${ }^{7}$ and estrogens. ${ }^{8}$ Medication guides are required for drugs that pose serious risks or require strict adherence to the prescribed regimen. ${ }^{9}$ Additional FDA-approved patient labeling includes instructions for use and patient information.

Patient-centered care aims to engage and empower patients in health care decision-making, resulting in improved health outcomes. ${ }^{10-12}$ One component of patient-centered care is providing patients with information to help them understand their diagnosis and treatment and promote engagement in decisions about their care alongside the provider. ${ }^{12}$ With respect to pharmacogenetic testing, it is not clear to what extent pharmacogenetic information is conveyed to patients by the provider or available to patients through FDA-approved patient-specific materials. Providers are encouraged to share the information in the patient counseling information (or information for patients for older drugs) section; therefore, if pharmacogenetic information is included in that section, it should increase patient awareness about pharmacogenetics.

In order to determine what information about pharmacogenetics, if any, is included in patient-targeted sections of the FDA-approved drug label, we conducted a review of the labels of medications known to have some pharmacogenetic information in the label. Although other analyses of drug labels for pharmacogenetic information have been conducted, ${ }^{1,13-17}$ our study appears to be the first to focus on patient-targeted sections and include a content analysis. The purpose of our analysis was to determine what pharmacogenetic information is included in sections of the drug label targeted to patients and determine if there are any patterns or consistencies in the information provided. Results from this analysis may aid in developing improved labels or resource supplements to encourage patient-provider discussion about pharmacogenetics and increase patient knowledge of pharmacogenetic information.

\section{Materials and methods}

To identify pharmacogenetic information in the patienttargeted sections of the drug label, we reviewed and conducted a content analysis of the most current version of the label for the drugs listed in the FDA's Table of Pharmacogenomic Biomarkers in Drug Labels ${ }^{2}$ using the links to the drug label provided in the table (updated and reviewed May 13, 2014). Although the sections containing information are also listed in the table, ${ }^{2}$ we observed that the list is incomplete for some drugs, potentially due to differences in definition of pharmacogenetic information between our study and the FDA. In our initial review, drug labels were selected for analysis if they contained the following within the specific sections analyzed: a specific gene (full name or symbol) or genetic terms, including "genetic", "genomic", "inherited", "hereditary", "gene”, "genotype", "carrier", "homozygous", "heterozygous", "chromosome", "deletion", "duplication", or "translocation". Although this methodology may not capture some labels with pharmacogenetic information, the key terms were selected because of their anticipated use in describing a genetic component or effect. For this analysis, we examined three specific sections of the overall drug label: the patient counseling information section (section 17) or information for patients section with older drugs; medication guide (if available); and FDA-approved patient information (if available).

A total of 35 drug labels with genetic-related information in one or more of the patient-targeted sections were identified (Figure 1). For these labels, the section(s) in which the information appeared, related adjacent sections, and the actual text for subsequent content analysis were recorded and analyzed. Since information about other genes or genetic diseases that are not related to pharmacogenetics may be included in the patient-targeted sections of the drug label, the 35 labels were reviewed again to specifically exclude labels or sections with information about other gene(s) not specified for that drug in the FDA table of Pharmacogenomic Biomarkers in Drug Labels. For example, some sections or drug labels were excluded if they only contain contraindications regarding drugs or foods that share metabolic pathways, or are associated with a pharmacogenetic gene different from the one listed in the FDA table (eg, cytochrome P450 3A4). In addition, drugs that include warnings for patients with 
FDA table of Pharmacogenomic

Biomarkers in Drug Labels $(n=140)$

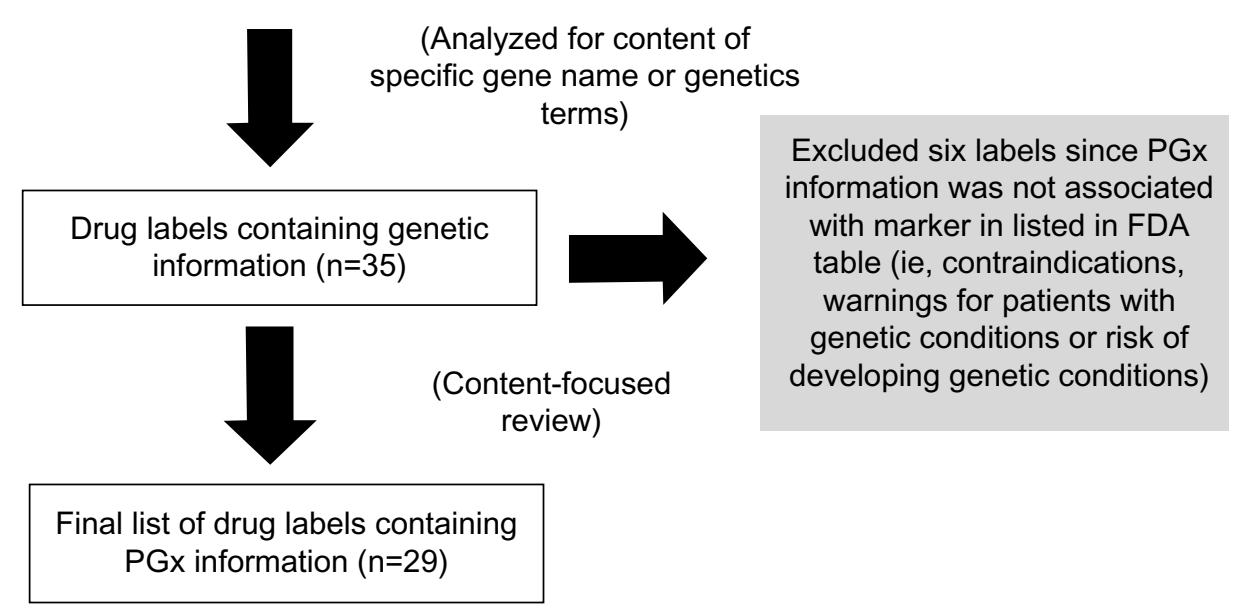

Figure I Schematic diagram of methodology.

Abbreviations: FDA, US Food and Drug Administration; PGx, pharmacogenetic.

other genetic conditions (eg, phenylketonuria) or risk of developing a new genetic condition were omitted. This second round of analysis reduced the initial list to 29 drugs for final analysis.

The final analysis entailed identifying characteristics or themes of the language or type of pharmacogenetic-related information included in patient-targeted sections of the drug label. Two of the authors conducted the content analysis and identified informational themes independently. Coding of themes was compared; agreement was found for $95 \%$ of pharmacogenetic texts, and differences were resolved through discussion with the third author. Only sections of the label that included the pharmacogenetic-specific search criteria were analyzed (see Table S1). Therefore, the amount of text analyzed for each drug was variable, dependent on the amount of pharmacogenetic-related information provided in the label, ranging from a single sentence or bullet point to a full paragraph or an entire bulleted section.

\section{Results \\ Overview}

Of the 140 labels for medications currently listed in the FDA table of Pharmacogenomic Biomarkers in Drug Labels, ${ }^{2}$ 53 labels include a medication guide (38\%), 26 labels include an FDA-approved patient information section (18\%), and 122 labels include a patient counseling section (or information for patients section for older drugs). We identified 35 drug labels with some type of genetic information in one or more of the patient-targeted sections. After reviewing the content of the
35 labels, we determined that six contain genetic information unrelated to the associated pharmacogenetic biomarker(s) listed in the FDA table, so excluded these from our content analysis. Three of the six excluded labels state that the drug is not to be used with inhibitors of cytochrome P450 3A4. The fourth excluded drug label states the unknown efficacy for patients with BRCA1/2 carriers, and the final two excluded labels referred to hepatitis $\mathrm{C}$ genotype 1. Thus, 29 drugs were included on our final list, accounting for $21 \%$ of the 140 drugs reviewed. Of special note, in our initial review of the labels, several drug labels were found to include warnings for patients with specific genetic diseases (eg, phenylketonuria) within the patient-targeted sections; but since they did not include any of our search terms (eg, describing the condition as genetic or noting the causative gene), they were not identified in our initial review.

Seventeen (59\%) of the 29 drugs have a medication guide and all include pharmacogenetic information (Table 1). Eleven $(36 \%)$ of the 29 drugs have FDA-approved patient information and ten of those eleven include pharmacogenetic information in this section, 24 of the 29 drugs include a patient counseling information section on the label, and six include pharmacogenetic information. Four of the 29 drugs include pharmacogenetic information in two patient-related sections.

Upon further analysis of the content and language of the three patient-targeted sections containing pharmacogeneticrelated information, we identified nine themes in total related to pharmacogenetics (Table 2) comprising: two themes 
Table I Summary of patient-related sections of drug labels listed in the FDA table of Pharmacogenomic Biomarkers in Drug Labels

\begin{tabular}{llll}
\hline $\begin{array}{l}\text { Patient-targeted } \\
\text { components }\end{array}$ & $\begin{array}{l}\text { Presence of patient-related section } \\
\text { in drug labeling** }(\mathbf{n}=\mathbf{1 4 0})\end{array}$ & $\begin{array}{l}\text { Our list of labels with } \\
\text { PGx information }(\mathbf{n}=\mathbf{2 9})\end{array}$ & $\begin{array}{l}\text { Sections containing PGx } \\
\text { information on our list of labels* }\end{array}$ \\
\hline $\begin{array}{l}\text { Medication guide } \\
\text { Patient information }\end{array}$ & $53(38 \%)$ & $17(59 \%)$ & $17 / 17(100 \%)$ \\
Patient counseling & $26(18 \%)$ & $11(38 \%)$ & $10 / 11(91 \%)$ \\
information section & $122(87 \%)$ & $24(83 \%)$ & $6 / 24(25 \%)$
\end{tabular}

Notes: *Four drugs included PGx information in more than one section; **all drugs listed in FDA PGx biomarkers table.

Abbreviations: FDA, US Food and Drug Administration; PGx, pharmacogenetic.

regarding the language about pharmacogenetic text (inclusion of gene name/symbol and genetic terms including "gene", "genetic", "genotype", or "inherited" to describe nature of condition or biomarker), three informational-oriented content themes (available test, at-risk or drug-targeted populations, and risk of side effects in patients with particular gene variant/ genetic condition), and four action-oriented content themes (dosage changes, discussion with physician, sharing of test results, stopping/not taking drug; see Table S1 for full text from patient-targeted sections used for content analysis). Of note, none of the patient-targeted materials used the term "pharmacogenetic".

\section{Pharmacogenetic information in the medication guide}

We found that, within the medication guide, the pharmacogenetic information was more likely to be for informational purposes than associated with specific actions. Twelve of the 17 medication guides include one or more types of information-oriented text. Ten medication guides include warnings of at-risk patient populations. For example, the label for the drug valproic acid ${ }^{18}$ states that patients that "have or think you have a genetic liver problem caused by a mitochondrial disorder (eg, Alpers-Huttenlocher syndrome)" should not take this drug. Two of those ten medication guides describe the increased risk of an adverse event in patients with a specific genetic variation (eg, the label forabacavir ${ }^{19}$ states "Your risk of this allergic reaction is much higher if you have a gene variation called HLA-B*5701"). Ten of the 17 medication guides include one or more action-oriented type of information, the primary action being for the patient to talk with their provider about the pharmacogenetic-related information $(\mathrm{n}=7)$. Another action-oriented item is a recommendation for the patient to discuss with their provider whether they have had testing. Only one medication guide includes recommendations for dosage adjustments or other clinical changes based on the pharmacogenetic information (the label for lenalidomide ${ }^{20}$ states "If you are being treated for deletion 5q myelodysplastic syndromes (MDS) your blood counts should be checked weekly during the first 8 weeks of treatment with Revlimid, and at least monthly thereafter"). Pharmacogenetic information is most commonly located within the medication guide in the first section (entitled "What is the most important information I should know") if related to an increased risk for a side effect, or in the second section (titled "What is [drug name]?") if about the target population of the drug. Regarding the language used to describe the pharmacogenetic information, 13 of the 17 medication guides include the gene name or symbol, and eight use the term "genetic" or "gene" or "inherited".

\section{Pharmacogenetic information in patient information material}

In the eleven drug labels with FDA-approved patient information that includes pharmacogenetic-related content, all specify a particular population for which the drug is indicated or contraindicated. Seven of the eleven patient information materials have a description of the target population for the drug. For example, the description of afatinib ${ }^{21}$ states that the drug is intended to treat non-small-cell lung cancer in patients with "certain types of abnormal epidermal growth factor receptor (EGFR) genes". Two include warnings against use of the drug in patients with specific genetic conditions or genotype (eg, capecitabine ${ }^{22}$ and 5 -flourouracil ${ }^{23}$ specify that patients with dihydropyrimidine dehydrogenase enzyme deficiency should not take the drug). One drug, dapsone, ${ }^{24}$ includes genotype-specific side effects by stating that individuals with glucose-6-phosphate dehydrogenase deficiency may be at greater risk for developing anemia upon taking the drug. With respect to the language used, five of the ten use the gene name or symbol and six use the term "gene", "genetic", or "inherited".

\section{Pharmacogenetic information in the patient counseling information section}

Of the six drugs that include pharmacogenetic content in the patient counseling information section, we found that the pharmacogenetic content is mostly informational, 


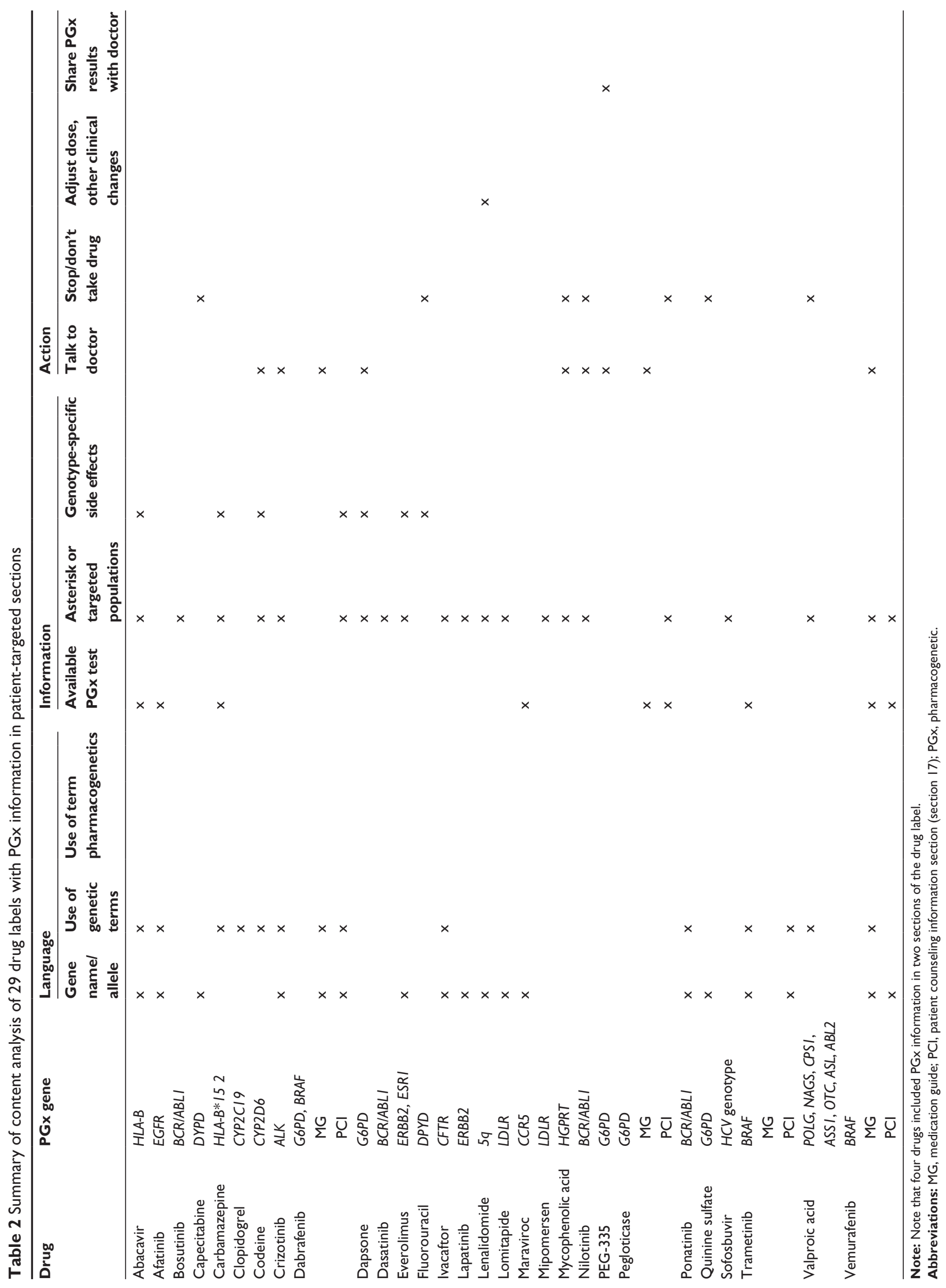


particularly about the indicated target population for the drug. Two labels (for codeine ${ }^{25}$ and pegloticase ${ }^{26}$ ) specify populations at risk for side effects. However, only pegloticase includes an action-oriented statement with instructions to not take the drug if the patient has a given genotype (the patient counseling information section for pegloticase states "Inform patients not to take Krystexxa ${ }^{\circledR}$ if they have a condition known as G6PD deficiency"). Four of the six patient counseling sections include the gene name or symbol. The patient counseling information section for the drug codeine includes the most pharmacogenetic-related information, with both genotype-specific side effects and action statements. For example, the codeine label instructs providers to advise nursing mothers taking codeine to watch for signs of morphine toxicity in their infant due to a possible genetic variation in the mother. Two drugs (pegloticase ${ }^{26}$ and vemurafenib ${ }^{27}$ ) include a statement suggesting genetic testing. Four of the six drugs that include pharmacogenetic information in the patient counseling information section also include it in the medication guide (exception was codeine).

\section{Discussion}

With growing patient interest in health information and engagement in health care decision-making as well as increased access to medical records, it is essential to make health information available and easy to understand for patients. Our finding of lack of inclusion and consistency regarding the type of pharmacogenetic information in patient sections of drug labels suggests that not all patients are made aware of pharmacogenetic information that may be useful in understanding the possible risks and benefits of taking their medication. Further, because pharmacogenetic content was more often included in the medication guide or patient information section than in the patient counseling sections, some patients may be exposed to pharmacogenetic information without the input of their provider, increasing the likelihood of confusion or anxiety. Since patients are likely to have difficulty in understanding information in medication guides, ${ }^{28-31}$ and specifically about pharmacogenetics, ${ }^{32}$ a lack of patient-provider discussion about pharmacogenetics may also result in confusion. In addition, if pharmacogenetic information is disclosed in the patient materials, but not in the patient counseling information section, providers may not be prepared to address patient inquiries about testing or the information provided may be incorrect. ${ }^{33}$

We speculate that the primary reason that pharmacogenetic information is not typically included in patienttargeted sections of the drug label is that the information is considered unnecessary "for patients to use the drug safely and effectively" (as specified by FDA guidance for the patient counseling section ${ }^{6}$ ) and that there is a lack of required or recommended action to be taken by the patient regarding pharmacogenetics. While knowledge of pharmacogenetics may not be relevant to use of a particular drug, patients may still appreciate and benefit from learning about potential genetic factors that may influence the response and risk of side effects. Indeed, patients have expressed interest in learning about both basic and specific clinical information regarding medications. ${ }^{34}$ Furthermore, the data suggest that patients may actually want to know more than providers assume they do. ${ }^{35}$ However, if the pharmacogenetic information for patients does not warrant any specific action (and most of the text analyzed was considered informational rather than action-oriented), disclosure may unduly burden patients with unnecessary information that may also be difficult to understand.

Studies suggest that the majority of patients read and appreciate the written materials dispensed with new medications. ${ }^{36,37}$ Patient-provider discussion about medication risks has been associated with patient review of written medication materials. ${ }^{38}$ For new medications, patients are often interested in understanding the reason for which a drug is prescribed, how and when to take the drug, and possible side effects, ${ }^{39}$ which would potentially include pharmacogenetic information. For prescription drugs, there are several opportunities for patients to learn about the indication and risks of a given treatment, through health providers and the patient-targeted information included with their prescriptions. However, interested patients can learn about pharmacogenetics from other sections of the drug label as well since they have access to the entire label online. In addition, the FDA has developed a number of resources to educate patients about medications available through the information for consumers website. ${ }^{40}$ Some pharmacogenetic testing companies such as YouScript provide patients with pharmacist phone support, online resources, and a printed card with their pharmacogenetic test results.

Inconsistencies in labeling may be addressed by a stricter protocol regarding placement of information and defined criteria for what information should be included in patient sections. ${ }^{14}$ Given differences in the perceived value of drugrelated information between patients and providers and the novelty of pharmacogenetics, it may be beneficial to consult with patients, providers, health educators, and industry through public meetings and focus groups. ${ }^{41}$ If it is determined that information about the impact of pharmacogenetic variants and testing is to be disclosed to patients, the next question is 
how best to convey this information. ${ }^{42}$ We noted that the language used in the medication guides and handouts is brief, and about half include the gene name or symbol. Even if included in the FDA-approved medication guide or patient counseling section, this may not be an effective strategy to raise awareness. Thus, it may be worthwhile to consider alternative approaches to raise patient awareness of the effects of genetic variants and potential need for pharmacogenetic testing. Some study limitations should be noted. Although we reviewed sections of the labels targeted to patients, patients may find useful information in other sections of the label. Because the initial list of drug labels to be analyzed was identified by the presence of gene/allele names or genetic-related terms, it is possible that other types of pharmacogenetic information may have been excluded in this review. Additionally, the pharmacogenetic information in older drug labels compared with more recently approved labels may differ due to different guidelines at the time of approval. Finally, although some assumptions may be made about the likelihood of patients receiving information on pharmacogenetics based on what information is available in labels, without observing and measuring discussions between patients and providers as well as patient information-seeking habits, it is not possible to know exactly what type of and amount of pharmacogenetic information patients are receiving. Therefore, additional research is warranted to explore patient-provider communication and patient awareness to better understand what information is made available to patients.

\section{Conclusion}

Efforts are needed to better understand what information patients need regarding the impact of pharmacogenetic variants on drug response and how best to incorporate that information into drug labels, clinical discussions, and elsewhere. Currently, the inconsistent presence of pharmacogenetic information in patient-specific sections of the drug label may cause confusion or worry. Public outreach may inform standardization of information about pharmacogenetics (or other clinical tests) disclosed to patients and the language used.

\section{Acknowledgment}

This work was supported by a grant from the National Institutes of Health (R01GM081416).

\section{Disclosure}

$\mathrm{SBH}$ is a paid consultant to the nonprofit Inova Translational Medicine Institute. The authors report no other conflicts of interest in this work.

\section{References}

1. Frueh FW, Amur S, Mummaneni P, et al. Pharmacogenomic biomarker information in drug labels approved by the United States Food and Drug Administration: prevalence of related drug use. Pharmacotherapy. 2008;28(8):992-998.

2. US Food and Drug Administration. Table of Pharmacogenomic Biomarkers in Drug Labels. Available from: http:/www.fda.gov/Drugs/ ScienceResearch/ResearchAreas/Pharmacogenetics/ucm083378.htm. Accessed May 13, 2014.

3. Charland SL, Agatep BC, Herrera V, et al. Providing patients with pharmacogenetic test results affects adherence to statin therapy: results of the Additional KIF6 Risk Offers Better Adherence to Statins (AKROBATS) trial. Pharmacogenomics J. 2014;14(3):272-280.

4. US Food and Drug Administration. Requirements on content and format of labeling for human prescription drug and biological products. January 24, 71 FR 3922. 2006; Code of Federal Regulations $\S \S 201.56$ and 201.57. Available from: http:/www.fda.gov/ohrms/ dockets/98fr/06-545.pdf. Accessed July 22, 2014.

5. US Food and Drug Administration. Labeling for human prescription drug and biological products - implementing the PLR content and format requirements. February 2013. Available from: http://www.fda. gov/downloads/Drugs/GuidanceComplianceRegulatoryInformation/ Guidances/ucm075082.pdf. Accessed May 13, 2014.

6. US Food and Drug Administration. Guidance for industry: patient counseling information section of labeling for human prescription drug and biological products - content and format. Sep 2013. Available from: http:/www.fda.gov/downloads/Drugs/Guidance ComplianceRegulatoryInformation/Guidances/UCM368602.pdf. Accessed May 13, 2014.

7. US Food and Drug Administration. Patient package inserts for oral contraceptives. Available from: http://www.accessdata.fda.gov/scripts/ cdrh/cfdocs/cfCFR/CFRSearch.cfm?fr=310.50121 CFR310.501. Accessed July 22, 2014.

8. US Food and Drug Administration. Patient package inserts for estrogens. 21CFR310.515. Available from: http:/www.accessdata.fda.gov/scripts/ cdrh/cfdocs/cfCFR/CFRSearch.cfm?fr=310.515. Accessed July 22, 2014.

9. US Food and Drug Administration. Medication guides for prescription drug products. 21CFR208. Available from: http://www.accessdata.fda. gov/scripts/cdrh/cfdocs/cfCFR/CFRSearch.cfm?fr=208.20. Accessed July 22, 2014.

10. Stewart M, Brown JB, Donner A, et al. The impact of patient-centered care on outcomes. J Fam Pract. 2000;49(9):796-804.

11. Weiner SJ, Schwartz A, Sharma G, et al. Patient-centered decision making and health care outcomes: an observational study. Ann Intern Med. 2013;158(8):573-579.

12. McMillan SS, Kendall E, Sav A, et al. Patient-centered approaches to health care: a systematic review of randomized controlled trials. Med Care Res Rev. 2013;70(6):567-596.

13. Conrado DJ, Rogers HL, Zineh I, Pacanowski MA. Consistency of drug-drug and gene-drug interaction information in US FDA-approved drug labels. Pharmacogenomics. 2013;14(2):215-223.

14. Seminerio MJ, Ratain MJ. Are drug labels static or dynamic? Clin Pharmacol Ther. 2013;94(3):302-304.

15. Drozda K, Muller DJ, Bishop JR. Pharmacogenomic testing for neuropsychiatric drugs: current status of drug labeling, guidelines for using genetic information, and test options. Pharmacotherapy. 2014;34(2):166-184.

16. Otsubo Y, Asahina Y, Noguchi A, Sato Y, Ando Y, Uyama Y. Similarities and differences between US and Japan as to pharmacogenomic biomarker information in drug labels. Drug Metab Pharmacokinet. 2012;27(1):142-149.

17. Shimazawa R, Ikeda M. Differences in pharmacogenomic biomarker information in package inserts from the United States, the United Kingdom and Japan. J Clin Pharm Ther. 2013;38(6):468-475.

18. Depakene (valproic acid): prescribing information; 2013. Available from: http://www.accessdata.fda.gov/drugsatfda_docs/label/2013/ 018081s056lbl.pdf. Accessed July 22, 2014. 
19. Ziagen (abacavir sulfate) medication guide; 2012. Available from: http:// www.fda.gov/downloads/Drugs/DrugSafety/ucm224556.pdf. Accessed July 22, 2014.

20. Revlimid (lenalidomide) medication guide; 2013. Available from: http:// www.fda.gov/downloads/Drugs/DrugSafety/ucm111335.pdf. Accessed July 22, 2014.

21. Gilotrif (afatinib) prescribing information; 2013. Available from: http:// www.accessdata.fda.gov/drugsatfda_docs/label/2013/201292s002lbl. pdf. Accessed July 22, 2014.

22. Xeloda (capecitabine) prescribing information; 2010. Available from: http://www.accessdata.fda.gov/drugsatfda_docs/label/2011/ 020896s026lbl.pdf. Accessed July 22, 2014.

23. Carac (fluorouracil) prescription information; 2003. Available from: http://www.accessdata.fda.gov/drugsatfda_docs/label/2003/ 20985slr004_carac_lbl.pdf. Accessed July 22, 2014.

24. Aczone (dapsone) prescribing information; 2009. Available from: http:// www.accessdata.fda.gov/drugsatfda_docs/label/2009/021794s006lbl. pdf. Accessed July 22, 2014.

25. Codeine sulfate prescribing information; 2013. Available from: http:// www.accessdata.fda.gov/drugsatfda_docs/label/2013/022402s006lbl. pdf. Accessed July 22, 2014.

26. Krystexxa (pegloticase) medication guide; 2012. Available from: http://www.fda.gov/downloads/Drugs/DrugSafety/UCM227568.pdf. Accessed July 22, 2014.

27. Zelboraf (vemurafenib) prescribing information; 2013. Available from: http://www.accessdata.fda.gov/drugsatfda_docs/label/2013/ 202429s002s003lbl.pdf. Accessed July 22, 2014.

28. Allen LaPointe NM, Pappas P, Deverka P, Anstrom KJ. Patient receipt and understanding of written information provided with isotretinoin and estrogen prescriptions. J Gen Intern Med. 2007;22(1):98-101.

29. Wolf MS, Davis TC, Shrank WH, Neuberger M, Parker RM. A critical review of FDA-approved medication guides. Patient Educ Counsel. 2006;62(3):316-322.

30. Wolf MS, King J, Wilson EA, et al. Usability of FDA-approved medication guides. J Gen Intern Med. 2012;27(12):1714-1720.

31. Shiffman S, Gerlach KK, Sembower MA, Rohay JM. Consumer understanding of prescription drug information: an illustration using an antidepressant medication. Ann Pharmacother. 2011;45(4):452-458.
32. Rose D, Russo J, Wykes T. Taking part in a pharmacogenetic clinical trial: assessment of trial participants understanding of information disclosed during the informed consent process. BMC Med Ethics. 2013;14:34.

33. Storm A, Benfeldt E, Andersen SE, Andersen J. Basic drug information given by physicians is deficient, and patients' knowledge low. J Dermatolog Treat. 2009;20(4):190-193.

34. Nair K, Dolovich L, Cassels A, et al. What patients want to know about their medications. Can Fam Physician. 2002;48:104-110.

35. Dickinson D, Raynor DK. What information do patients need about medicines? Ask the patients - they may want to know more than you think. BMJ. 2003;327(7419):861.

36. McCormack JP, Dolovich L, Levine M, et al. Providing evidence-based information to patients in general practice and pharmacies: what is the acceptability, usefulness and impact on drug use? Health Expect. 2003;6(4):281-289.

37. Nathan JP, Zerilli T, Cicero LA, Rosenberg JM. Patients' use and perception of medication information leaflets. Ann Pharmacother. 2007;41(5):777-782.

38. Schmitt MR, Miller MJ, Harrison DL, et al. Communicating nonsteroidal anti-inflammatory drug risks: verbal counseling, written medicine information, and patients' risk awareness. Patient Educ Counsel. 2011;83(3):391-397.

39. Raynor DK, Savage I, Knapp P, Henley J. We are the experts: people with asthma talk about their medicine information needs. Patient Educ Counsel. 2004;53(2):167-174.

40. US Food and Drug Administration. Information for Consumers (drugs). 2014. Available from: http://www.fda.gov/Drugs/ResourcesForYou/ Consumers/default.htm. Accessed May 13, 2014.

41. US Food and Drug Administration. Development and distribution of patient medication information for prescription drugs; public hearing. US Department of Health and Human Services Federal Register. 2010;75(166):52765-52768. Available from: http:/www.fda.gov/drugs/ newsevents/ucm219716.htm. Accessed July 22, 2014.

42. Berry DC, Raynor DK, Knapp P, Bersellini E. Patients' understanding of risk associated with medication use - impact of European Commission guidelines and other risk scales. Drug Saf. 2003;26(1): $1-11$. 


\section{Supplementary material}

Table SI Patient-targeted sections of drug labels used for content analysis (due to copyright restrictions, we are not able to provide the full text used in the content analysis but refer the reader to the noted section in the drug label at the provided URL accessible through the US Food and Drug Administration)

\begin{tabular}{|c|c|c|}
\hline Drug & Source & URL for drug label \\
\hline Abacavir & MG & http://www.fda.gov/downloads/Drugs/DrugSafety/ucm224556.pdf \\
\hline Afatinib & PI & http://www.accessdata.fda.gov/drugsatfda_docs/label/2013/201292s002lbl.pdf \\
\hline Bosutinib & $\mathrm{PI}$ & http://www.accessdata.fda.gov/drugsatfda_docs/label/2013/20334/ s00 Ilbl.pdf \\
\hline Capecitabine & $\mathrm{PI}$ & http://www.accessdata.fda.gov/drugsatfda_docs/label/201 I/020896s026lbl.pdf \\
\hline Carbamazepine & MG & http://www.accessdata.fda.gov/drugsatfda_docs/label/2014/016608s $103,018281 \mathrm{~s} 051,018927 \mathrm{~s} 044,020234 \mathrm{~s} 035 \mathrm{lbl}$.pdf \\
\hline Codeine & $\mathrm{PCl}$ & http://www.accessdata.fda.gov/drugsatfda_docs/label/2013/022402s006/bl.pdf \\
\hline Clopidogrel & MG & http://www.fda.gov/downloads/Drug/DrugSafety/UCM243349.pdf \\
\hline Crizotinib & PI & http://www.accessdata.fda.gov/drugsatfda_docs/label/2013/202570s006lbl.pdf \\
\hline Dabrafenib & MG, PCl & http://www.accessdata.fda.gov/drugsatfda_docs/label/20|4/202806s002lbl.pdf \\
\hline Dapsone & $\mathrm{PI}$ & http://www.accessdata.fda.gov/drugsatfda_docs/label/2009/021794s006lbl.pdf \\
\hline Dasatinib & PI & http://www.accessdata.fda.gov/drugsatfda_docs/label/2014/021986s0|4lbl.pdf \\
\hline Everolimus & PI & http://www.accessdata.fda.gov/drugsatfda_docs/label/20I4/022334s02Is023s024,203985s002s004s005lbl.pdf \\
\hline Fluorouracil & PI & http://www.accessdata.fda.gov/drugsatfda_docs/label/2003/20985slr004_carac_lbl.pdf \\
\hline Ivacaftor & PI & http://www.accessdata.fda.gov/drugsatfda_docs/label/2014/203/88s008lbl.pdf \\
\hline Lapatinib & $\mathrm{PI}$ & http://www.accessdata.fda.gov/drugsatfda_docs/label/2013/022059s016s017lbl.pdf \\
\hline Lenalidomide & MG & http://www.fda.gov/downloads/Drugs/DrugSafety/ucm I | |335.pdf \\
\hline Lomitapide & MG & http://www.fda.gov/downloads/Drugs/DrugSafety/UCM333530.pdf \\
\hline Maraviroc & MG & http://www.fda.gov/downloads/Drugs/DrugSafety/ucm089122.pdf \\
\hline Mipomersen & MG & http://www.fda.gov/downloads/Drugs/DrugSafety/UCM337730.pdf \\
\hline Mycophenolic Acid & MG & http://www.fda.gov/downloads/Drugs/DrugSafety/UCMI72735.pdf \\
\hline Nilotinib & MG & http://www.accessdata.fda.gov/drugsatfda_docs/label/2014/022068s0I7lbl.pdf \\
\hline PEG-3350 & MG & http://www.fda.gov/downloads/Drugs/DrugSafety/UCM253840.pdf \\
\hline Pegloticase & MG, PCl & http://www.fda.gov/downloads/Drugs/DrugSafety/UCM227568.pdf \\
\hline Ponatinib & MG & http://www.accessdata.fda.gov/drugsatfda_docs/label/2012/203469s000mg.pdf \\
\hline Quinine Sulfate & MG & http://www.fda.gov/downloads/Drugs/DrugSafety/UCM192698.pdf \\
\hline Sofosbuvir & $\mathrm{PCl}$ & http://www.accessdata.fda.gov/drugsatfda_docs/label/2013/20467/ s000lbl.pdf \\
\hline Trametinib & MG, PCl & http://www.accessdata.fda.gov/drugsatfda_docs/label/20|4/204||4s00||bl.pdf \\
\hline Valproic Acid & MG & http://www.accessdata.fda.gov/drugsatfda_docs/label/2013/01808/ s056lbl.pdf \\
\hline Vemurafenib & MG, PCl & http://www.accessdata.fda.gov/drugsatfda_docs/label/2014/202429s004lbl.pdf \\
\hline
\end{tabular}

Abbreviations: MG, medication guide; PI, patient information; $\mathrm{PCl}$, patient counseling information section (section I7).

\section{Publish your work in this journal}

Pharmacogenomics and Personalized Medicine is an international, peerreviewed, open access journal characterizing the influence of genotype on pharmacology leading to the development of personalized treatment programs and individualized drug selection for improved safety, efficacy and sustainability. This journal is indexed on the American Chemical
Society's Chemical Abstracts Service (CAS). The manuscript management system is completely online and includes a very quick and fair peer-review system, which is all easy to use. Visit http://www.dovepress. $\mathrm{com} /$ testimonials.php to read real quotes from published authors.

\footnotetext{
Submit your manuscript here: http://www.dovepress.com/pharmacogenomics-and-personalized-medicine-journal
} 